Sci. Journal Impact

Factor: 6.1 (2018)

ICV: 90.90 (2018)

(c) (i) (3)

Copyright@IJCRR

\section{$\bullet$ \\ IJCRR \\ Section: Healthcare \\ Evaluation of Functional Outcome of Minimally Invasive Percutaneous Plate Osteosynthesis in the Management of Proximal Tibial Plateau Fractures}

\author{
Santosh Kumar Sahu' ${ }^{1}$, Abhishek Pandey²
}

'Assistant Professor, Department of Orthopaedics, IMS\&SUM Hospital, SOA University, Bhubaneswar, India; ${ }^{2}$ PGT, Department of Orthopaedics, IMS \& SUM Hospital, SOA University, Bhubaneswar, India.

\title{
ABSTRACT
}

Background: The management of plateau fractures of the tibia with minimally invasive percutaneous plating osteosynthesis has been a revelation. It has avoided many complications such as a large surgical scar, disruption of musculo osseous vascularity. It has significantly enhanced the preservation of soft tissues circulation and biologic fixation mechanism. The management of these fractures patterns can be done with indirect manipulation and effective reduction techniques.

Methods: The details of the patients were recorded soon after the admission process, after documentation of history and examining them clinically. The fracture patterns were classified as per Schatzger, radiologically. Two approaches were followed:anterolateral and anteromedial for all the patients. The follow up was done in 6-8 weeks intervals. The period of study was from March 2018 to March 2020 which included 38 patients of the age group from 20-75 years.

Results: Out of 38 patients, the maximum number of patients were of the age group from 20-50 years (68\%). Schatzger's type 4 and 5 constituted the maximum number of fracture types, as per classification associated with high velocity injuries.1patient had joint stiffness, 2 patients had wound infection and the equal number of patients had varus deformity.26 patients showed excellent results, good results in 6 cases and fair and poor results were obtained in 3 cases each.

Conclusion: MIPPO technique for fractures of the proximal tibia had a very good outcome in terms of healing and also facilitated strong bone union due to the advantage of biological preservation of fracture site and less tissue damage.

Key Words: Proximal tibia fractures, Minimally invasive percutaneous plate osteosynthesis, Functional outcome

\section{INTRODUCTION}

The tibial plateau fractures can be devastating as they affect knee function and stability. ${ }^{1}$ They are also known bumper car fractures in literature. ${ }^{2}$ Fractures of these variations result from compressive forces, directed axially, most common being valgus or varus directed force and indirect shear. ${ }^{3} \mathrm{As}$ these are high energy fractures, the usual ORIF(open reduction and internal fixation) can result in wound breakdown and deep infection, which is based on laboratory and clinical studies. ${ }^{4}$ Older individuals owing to their poor bone density at the subchondral level, very commonly present with depression fractures and presumed to be weaker to resist any axial load. ${ }^{5}$ As MIPPO is a method of bridging the fracture by osteosynthesis, it can be done without significantly sacrificing the soft tissues, which preserves the reduction of fracture and bone-forming capacity of the fracture hematoma ${ }^{6,7}$ As surgi- cal treatment is the method of choice for the management of proximal tibial fractures, it can be also managed by cast bracing, traction, immobilization as an alternative to surgical intervention. The surgical methods despite being a conventional approach for the management of these fractures had disadvantages such as large surgical scars, wound dehiscence and intraoperative blood loss. It also had other notable issues such as hardware complications and alignment problems. These shortcomings have been solved by MIPPO to a great extent.

\section{MATERIALS AND METHODS}

This is a prospective study done from March 2018 to March 2020 at IMS and SUM Hospital. A total of 38 cases were chosen with the youngest being 20 years old and the eldest

\section{Corresponding Author:}

Dr. Abhishek Pandey, PGT, Department of Orthopaedics, IMS\&SUM Hospital, SOA University, Bhubaneswar, India. Email: dr.abhip87@gmail.com

ISSN: 2231-2196 (Print)

Received: 19.07 .2020
ISSN: $0975-5241$ (Online)

Revised: 07.08 .2020
Accepted: 10.09 .2020 
being 70 years old. All patients were thoroughly examined, and all the data were recorded. All the patients were evaluated for associated soft tissue injuries and were followed as per Schatzger's classification, radiologically. All patients with Gustilo-Anderson type 2 or 3, pathological fractures excepting osteoporosis, patients having compartment syndrome, fractures in children who have an intact growth plate and patients managed conservatively were excluded from our study.

All cases included in our study were managed with MIPPO using locking compression and buttressingplates. Before the surgery, the fracture was immobilized with plaster of Paris slab application along with limb elevation. Surgery was not undertaken until favourable healing of soft tissues were noted and the swelling around the knee joint had decreased significantly. Patients planned for the surgery received prophylactic $3^{\text {rd }}$ generation cephalosporins, 30 mins before the skin incision. There was planning made before the surgery, which considered:-length of the plate required, the number of screws to be used(approximate)as per the fracture pattern and abiding by the principles of fracture fixation in mind.

Patients were placed on a fracture table in a supine position with spinal anaesthesia being given. They were assessed for fracture configuration under image intensifier. Two approaches were commonly used: anterolateral and anteromedial (Figure 1). An incision of about $2 \mathrm{~cm}$ was made above the fracture site and space was created beneath using a periosteal elevator. The appropriate length of the implant was chosen (preferably a $\mathrm{T} /$ compressive locking plate) after placing it over the anterior aspect of the leg and visualizing it under fluoroscopic guidance just below the line made by the joint with the bottom end extending the last limit of tibial fracture so that it extends at least 3 screw holes. Another 2 $\mathrm{cm}$ incision was given where the distal tip of the plate lies. Plate contouring was necessary to secure it with approximate locking/cortical or cancellous screws of the required length.

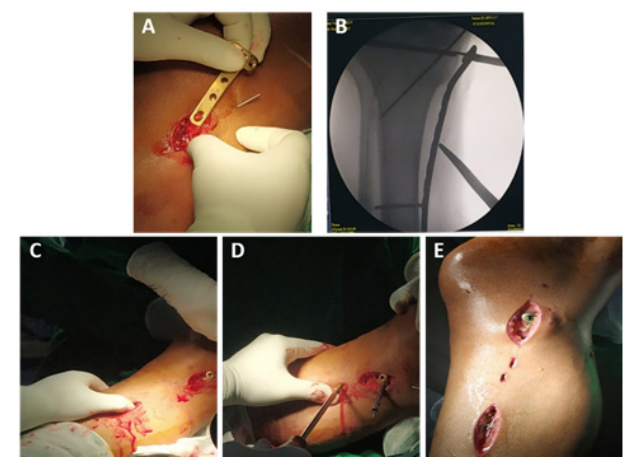

Figure 1: Represents different stages of wound processing. A. Skin incision and placement of the implant in the submuscular plane, B. Placement of the plate under C-arm guidance, C. Implant placement, D. locking screw application and E. final MIPPO.
Postoperative radiographs were done to assess the reduced fracture. Static quadriceps and active knee immobilization were started on day 1 . The decision for weight-bearing was not initiated until any evidence of bony union was noted, radiologically. Weight-bearing without support was only initiated until there was a clear sign of fracture site consolidation. The fracture healing was tracked as per routine anteroposterior and lateral radiographs. Radiographs were done at 6-8 weeks intervals up to 24 weeks, then every 3 months and every 6 months thereafter. The outcomes as per functional assessment were noted as per the criteria. ${ }^{8}$

\section{RESULTS}

Out of the 38 patients of proximal tibia fractures treated with MIPPO, the majority were around the age group of 20-50 years (Table 1) which are known to be highly mobile, therefore susceptible to vehicular injuries. Out of 38 patients, 26 were males $(68 \%)$ and the rest $12(32 \%)$ were females. 22 patients had fractures on the right side and 16 patients had fractures on the left, which was not that significant from the statistical point of view (Figure 2).

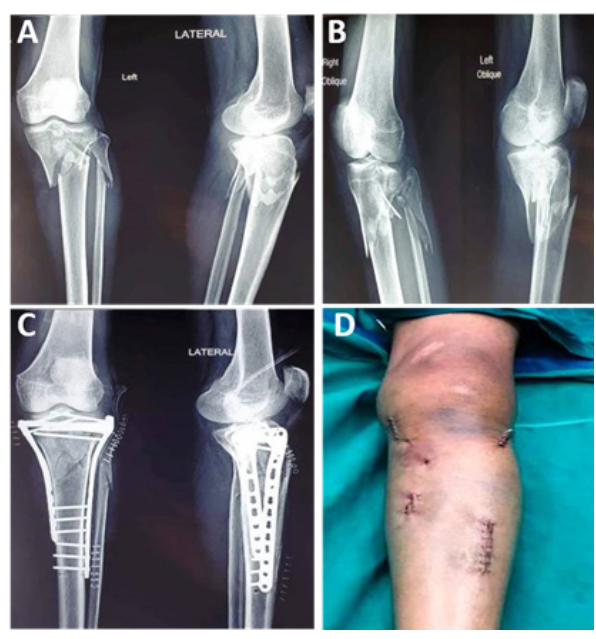

Figure 2: Represents Preoperative and post-operative images after the procedure.

Table 1: Age distribution of patients participated in study

\begin{tabular}{ccc} 
Age(years) & No. of patients & Percentage(\%) \\
$20-30$ & 6 & 15 \\
$31-40$ & 12 & 31 \\
$41-50$ & 8 & 21 \\
$51-60$ & 7 & 18 \\
$>60$ & 5 & 13 \\
\hline
\end{tabular}

Most fractures were of Schatzger's IV and V, which are most associated with high-speed vehicular accidents. 


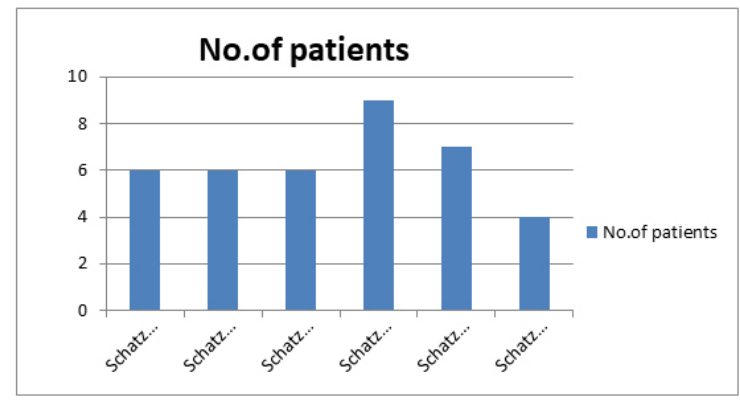

Figure 3: Types of fractures of as per Schatzger's classification.

From the complications point of view,1 patient had joint stiffness postoperatively.2 patients had wound infections and another 2 patients had varus deformity. The wound infection was effectively managed by meticulous debridement and antibiotics. The patient who had stiffness of the joint also had associated supracondylar femur fracture. Varus deformity was due to medial condylar collapse postoperatively (table 1 and 2).

Table 2: Complications faced by patients after surgery

\begin{tabular}{lcc} 
Complications & No. of Patients & Percentage(\%) \\
Joint stiffness & 1 & 2.5 \\
Wound infection & 2 & 5 \\
Varus deformity & 2 & 5 \\
\hline
\end{tabular}

Out of 38 patients, 26 patients had excellent, 6 had good,3 patients had fair outcomes and an equal number had poor results, as per Rassmussen's criteria (Figure 3,4).

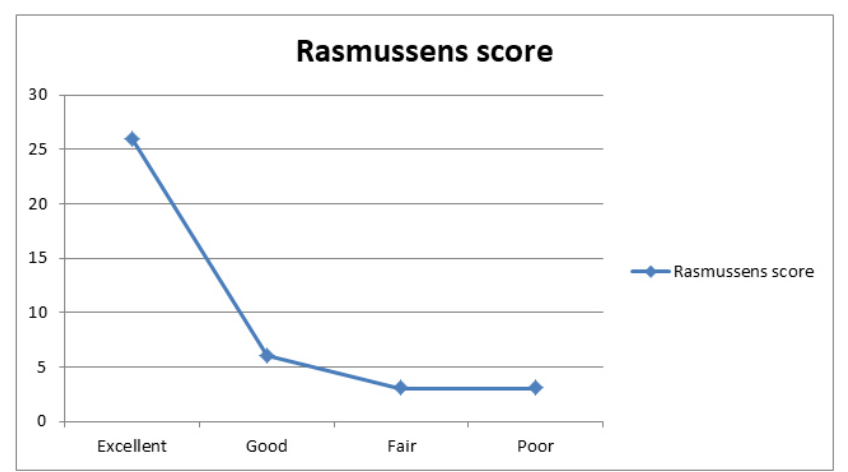

Figure 4: Rasmussens Score.

\section{DISCUSSION}

Proximal tibial fractures have increased in number because of the increase in road traffic accidents which causes comminution at the fracture site. ${ }^{8,9}$ As these fractures are around the knee joint, these result in significant morbidity. These types of fractures are difficult to treat because it has increased the number of complications. ${ }^{10-12}$ There is a male preponderance concerning epidemiology as described by Kretekk and Koval. ${ }^{13,14}$ Joon Woo Kim believed, that majority of fractures occurred in the range of 24-69 years with a mean age of 44.4 years. ${ }^{15}$ Gonzalez et al described that the plate (locking) can be used with severe soft tissues damage as the plates tend to preserve the periosteal blood supply and further need for bone grafting. MIPPO enables indirect fracture reduction and percutaneous submuscular implant placement. ${ }^{16}$ In a study of ORIF, about $20 \%$ of the patients encountered infections, ranging from superficial to deep, despite satisfactory outcome. ${ }^{17}$ MIPPO results in less number of soft tissue issues and accomplishes better outcome than the other method of openly reducing it. ${ }^{18-21}$ Elderly patients tend to have osteoarthritic changes in the joints, which aggravates after intraarticular fractures, where the age of the patient is the main predictor of functional outcome. ${ }^{22}$ MIPPO reduces pain in the post-operative period and enables early rehabilitation, which directly has the effect of regaining articular cartilage function and healing. ${ }^{23}$ Long term follows up is necessary because they tend to produce secondary osteoarthritis. ${ }^{24}$

\section{CONCLUSION}

As the number of road traffic accidents have increased, the management of these complex fractures has changed immensely. Majority of the patients sustaining these pattern of fractures are related to the group of active mobility. Therefore, they need an effective management strategy to return to their optimal routine. MIPPO provides them with a medium in doing so, as it is related to a lesser number of complications, effective resumption of active knee movement and minimal surgical scar. It also gives them a better bony union and fracture fixation due to inherent qualities of minimal tissue damage and stable biological fixation.

\section{ACKNOWLEDGMENT}

Authors acknowledge the immense help received from the scholars whose articles are cited and included in references to this manuscript. The authors are also grateful to authors / editors / publishers of all those articles, journals, and books from which the literature for this article has been reviewed and discussed.

Funding-no funding sources

Conflict of interest-None declared

\section{REFERENCES}

1. Raza H, Hashmi P, Abbas K, Hafeez K. Minimally invasive plate osteosynthesis for tibial plateau fractures. J Orthop Surg 2012 Apr;20(1):42-7. 
2. Cotton FJ, Berg R. Fender fracture of the tibia at the knee. New Eng J Med 1929 Nov 14;201(20):989-95.

3. Koval KJ, Helfet DL. Tibial plateau fractures: evaluation and treatment. J Am Acad Orthop Surg 1995;3(2):86-94.

4. Ruedi TP. AO principles of fracture management. Thieme. 2000.

5. Biyani A, Reddy NS, Chaudhury J, Simison AJ, Klenerman L. The results of surgical management of displaced tibial plateau fractures in the elderly. Injury 1995 Jun;26(5):291-297.

6. Oh CW, Kyung HS, Park IH, Kim PT, Ihn JC. Distal tibia metaphyseal fractures treated by percutaneous plate osteosynthesis. Clin Orthop Relat Res 2003 Mar;408:286-91.

7. Redfern DJ, Syed SU, Davies SJ. Fractures of the distal tibia: minimally invasive plate osteosynthesis. Injury 2004 Jun;35(6):615-20.

8. Savoie FH, Vander Griend RA, Ward EF, Hughes JL. Tibial plateau fractures: a review of operative treatment using AO technique. Orthopedics 1987 May;10(5):745-50.

9. Lansinger O, Bergman B, Körner L, Andersson GB. Tibial condylar fractures. A twenty-year follow-up. J Bone Joint Surg 1986 Jan;68(1):13-9.

10. Young M, Barrack RL. Complications of internal fixation of tibial plateau fractures. Orthop Rev 1994 Feb;23(2):149.

11. Schatzker J, Mcbroom R, Bruce D. The tibial plateau fracture: the Toronto experience 1968-1975. Clin Orthop Relat Res 1979; 1(138):94-104.

12. Papagelopoulos PJ, Partsinevelos AA, Themistocleous GS, Mavrogenis AF, Korres DS, Soucacos PN. Complications after tibia plateau fracture surgery. Injury 2006 Jun 1;37(6):475-84.

13. Krettek C, Gerich T, Miclau TH. A minimally invasive medial approach for proximal tibial fractures. Injury 2001 May;32:4-13.

14. Koval KJ, Helfet DL. Tibial plateau fractures: evaluation and treatment. J Am Acad Orthop Surg 1995 Mar;3(2):86-94.

15. Kim JW, Oh CW, Jung WJ, Kim JS. Minimally invasive plate osteosynthesis for open fractures of the proximal tibia. Clin Orthop Surg 2012 Dec;4(4):313-20.
16. Cole PA, Zlowodzki M, Kregor PJ. Less Invasive Stabilization System (LISS) for fractures of the proximal tibia: indications, surgical technique and preliminary results of the UMC Clinical Trial. Injury 2003 Aug;34:A16.

17. Barei DP, Nork SE, Mills WJ, Henley MB, Benirschke SK. Complications associated with internal fixation of high-energy bicondylar tibial plateau fractures utilizing a two-incision technique. J Orthop Trauma 2004;18(10):649-57.

18. Kumar A, Whittle AP. Treatment of complex (Schatzker Type VI) fractures of the tibial plateau with circular wire external fixation: retrospective case review. J Orthop Trauma 2000 Jun;14(5):339-44.

19. Chin TY, Bardana D, Bailey M, Williamson OD, Miller R, Edwards ER, Esser MP. Functional outcome of tibial plateau fractures treated with the fine-wire fixator. Injury $2005 \mathrm{Dec}$ 1;36(12):1467-75.

20. Stannard JP, Wilson TC, Volgas DA, Alonso JE. The less invasive stabilization system in the treatment of complex fractures of the tibial plateau: short-term results. J Orthop Trauma 2004 Sep 1;18(8):552-8.

21. Cole PA, Zlowodzki M, Kregor PJ. Treatment of proximal tibia fractures using the less invasive stabilization system: surgical experience and early clinical results in 77 fractures. J Orthop Trauma 2004 Sep 1;18(8):528-35.

22. Stevens D, Beharry R, Waddell JP, Schemitsch EH. Long term functional outcome of operatively treated tibial plateau fractures. J Orthop Trauma 1999 May 1;13(4):295-6.

23. Gausewitz ST, Hohl MA. The significance of early motion in the treatment of tibial plateau fractures. Clin Orthop Relat Res 1986 $\operatorname{Jan}(202): 135-8$.

24. Katsenis D, Dendrinos G, Kouris A, Savas N, Schoinochoritis N, Pogiatzis K. Combination of fine wire fixation and limited internal fixation for high-energy tibial plateau fractures: functional results at minimum 5-year follow-up. J Orthop Trauma 2009 Aug 1;23(7):493-501. 